\title{
Von der Währungsunion zur (gescheiterten) Konstitutionalisierung der Europäischen Union - zehn Jahre Systemreform, ein Kapitel Integrationsgeschichte (1999-2008)
}

\author{
Hartmut Marhold*
}

Der Ausgangspunkt: die Währungsunion als Auslöser der Reformdebatte?

„Mit dem 1. Januar 1999 und der Einführung des Euro, der gemeinsamen Währung, durch elf Mitgliedstaaten, hat Europa einen historischen, ja vielleicht sogar revolutionären Schritt getan, der dem europäischen Integrationswerk eine neue Qualität verleihen wird. [...] Währung, Sicherheit und Verfassung, das sind die drei wesentlichen Souveränitäten der modernen Nationalstaaten, und mit der Einführung des Euro wurde ein erster Schritt zu ihrer Vergemeinschaftung in der EU getan. [...] Die um neue Mitgliedsstaaten vergrößerte politische Union muß von nun an unser Kompaß sein, sie ist die logische Konsequenz der Wirtschafts- und Währungsunion."1

„Der europäische Einigungsprozeß hat mit der Wirtschafts- und Währungsunion eine qualitativ neue Stufe erreicht, die weitreichende Konsequenzen [...] erfordert. Tatsächlich [...] wird wieder heftiger die Frage debattiert, worauf der europäische Einigungsprozeß denn eigentlich hinausläuft. Letztlich ist es die Frage danach, wie die Europäische Union und ihre Mitgliedstaaten rechtlich und politisch verfasst sein sollen.“2

Inzwischen liegt der Start der Reformdebatte der Europäischen Union ein Jahrzehnt zurück - zehn Jahre, nicht nur acht oder sieben: Der Vertrag von Nizza, im Dezember 2000 unterzeichnet, war schon ein erster Versuch, die Fragen von 1999 zu lösen, ein allerdings derart unbefriedigender Versuch, dass der Eindruck entstehen konnte, die Reform habe erst danach angefangen und womöglich erst mit den Arbeiten des Konvents Ende Februar 2002. Aber Joschka Fischer, Wolfgang Schäuble und Karl Lamers sind Zeugen dafür, dass die Einführung des Euro, das Erreichen der Währungsunion (wenn auch nicht ihre Vollendung) die Reformdebatte in Gang setzten. Für zwei Jahrzehnte, seit der Einheitlichen Europäischen Akte, waren die politischen und intellektuellen Energien durch die großen Politikprojekte des Binnenmarktes und der Währungsunion gebunden, alle Kraft konzentrierte sich auf ihre Realisierung; das Nachdenken über eine gründliche Systemreform oder gar Verfassungsfragen überlebte nur in marginalen Zirkeln. ${ }^{3}$ Zwar waren die Herausforderungen, die über die Wirtschafts- und Währungsunion hinauswiesen, bereits präsent: die Dysfunktionalität der

\footnotetext{
Prof. Dr. Hartmut Marhold, Generaldirektor, Centre international de formation européenne, Nizza/Berlin.

1 Joschka Fischer: Rede des Vorsitzenden des Rates der Europäischen Union Joschka Fischer, Bundesminister des Auswärtigen, vor dem Europäischen Parlament; Straßburg, 12. Januar 1999, zitiert nach: Hartmut Marhold (Hrsg.): Die neue Europadebatte. Leitbilder für das Europa der Zukunft, Bonn 2001, S. 30.

2 Karl Lamers/Wolfgang Schäuble: Europa braucht einen Verfassungsvertrag. Überlegungen zur europäischen Politik II - zum Fortgang des europäischen Einigungsprozesses, Bonn, 3. Mai 1999, zitiert nach: Marhold: Die neue Europadebatte, 2001, S. 83.

3 Allerdings sollte nicht vergessen werden, dass die Debatte über eine europäische Verfassungsbildung die europäische Integration von Anfang an begleitet hat, ja ihr vorausging. Vgl. dazu Wilfried Loth: Entwürfe einer europäischen Verfassung. Eine historische Bilanz, Bonn 2002; zuvor schon Walter Lipgens (Hrsg.): 45 Jahre Ringen um die Europäische Verfassung. Dokumente 1939-1984, Bonn 1986.
} 
EU-Entscheidungsverfahren; die wachsende Kluft zwischen immer mehr europäischen Kompetenzen und immer geringerer Akzeptanz bei den Bürgern; die Erweiterung um die östliche Hälfte des Kontinents nach dem Fall der Mauer; die aktive Annahme von Verantwortung in einer zunehmend komplex vernetzten Weltpolitik; et cetera. Aber diese Aufgaben, die nun Motive der Reformdebatte wurden, konnten sich vor 1999 auf den Agenden der Staats- und Regierungschefs, der Minister und Kommissare, der Abgeordneten des Europäischen Parlaments und Sachverständigen gegen die übermächtigen Ansprüche, die aus der Herkules-Aufgabe der Währungsunion erwuchsen, nicht durchsetzen. So lässt sich - selten in der Geschichte - der Beginn des Reformprozesses auf den Tag genau datieren: Am 1. Januar 1999 war das Ziel der Währungsunion tatsächlich erreicht und damit wurden die so lange gebundenen Energien frei, die Frage, worauf der europäische Einigungsprozess denn eigentlich hinausläuft, konnte gestellt werden, die politische Union wurde zum Kompass für die nächste, zehnjährige Phase der europäischen Integration. ${ }^{4}$

Jedenfalls gilt das für ihre innere Entwicklung, für ihre ,Vertiefung ' - daneben lief der ebenso bedeutsame politische Prozess der Erweiterung um die ostmittel- und südosteuropäischen Staaten weiter, der bekanntlich 2004/2007 zur ,Wiedervereinigung ' Europas und damit fast zur Verdoppelung der Zahl der Mitgliedstaaten führte. Für die neuen Mitglieder stellt sich die letzte Phase der europäischen Integration wiederum in anderer Periodisierung dar: Für sie ist der Vertrag von Nizza nicht in erster Linie ein (fast völlig) gescheiterter Versuch zur Fortentwicklung des politischen Systems der Europäischen Union, sondern die formale, ja mehr noch die förmliche Vorbereitung der Union auf die Aufnahme der neuen Mitgliedstaaten. Für viele Ostmitteleuropäer ist deshalb die Erinnerung an ,Nizza' weit positiver besetzt als für die ,Schon'-Mitglieder, der Vertrag von Nizza ist für sie die Referenz, die Instandsetzung der Europäischen Union für die Erweiterung, der Rahmen, der ihnen den Zutritt ermöglichte. ${ }^{5}$ Die Diskrepanz zwischen alten und neuen Mitgliedstaaten in der Einschätzung des Vertrags von Nizza barg Konfliktpotenzial für die weitere Reformbereitschaft, das sich später in Kontroversen um den Vertrag über eine Verfassung für Europa (Verfassungsvertrag) entlud. ${ }^{6}$

Trotz aller divergierenden Perzeptionen: Vieles spricht dafür, den Beginn der Reformphase auf den Januar 1999 zu datieren, auch wenn die Problemlagen schon länger bestanden, auch wenn ,Nizza' in den Augen der einen die Vertragserneuerung erst in Gang brachte und in den Augen anderer einen Fixpunkt bietet. Der ganze, nun also gut zehnjährige Prozess hat in der Tat alle Charakterzüge einer eigenen historischen Phase, mit Höhen und Tiefen, Hoffnungen und Enttäuschungen, Verzögerungen und Beschleunigungen, mit deutlich erkennbaren Teilabschnitten, mit innerer Logik und Interferenzen von außen. ${ }^{7}$

4 Zur Bedeutung des Zeitpunkts der Einführung der gemeinsamen Währung vgl. das in Frankreich viel gelesene Buch des dort renommierten Wirtschaftswissenschaftlers Jean Boissonnat: La Révolution de 1999. L'Europe avec l'Euro, Paris 1998.

5 Vgl. Gesa-Stefanie Brincker/Mathias Jopp/Rovná Lenka (Hrsg.): Leitbilder for the Future of the European Union. Dissenting Promoters of Unity, Baden-Baden 2011.

6 Ein eklatantes Beispiel dafür ist der viel zitierte Ausruf des polnischen Abgeordneten Jan Maria Rokita im polnischen Parlament: „Nizza oder der Tod!“. Vgl. Natalja Reiter: Ich, der Diktator, in: Die Zeit, 17.06.2004.

7 Freilich bleibt jede historische Erzählung dieses Kapitels der Integrationsgeschichte zunächst unter dem Vorbehalt, dass bei Weitem nicht alle, aber doch im Vergleich zu früheren Epochen ungewöhnlich viele Quellen zugänglich sind. 


\section{Zwischen hochgestimmten Leitbildern und Leiden an der integrationspolitischen Realität (Januar 1999 bis Dezember 2000)}

\section{Pläne für ein zu Ende gedachtes Europa}

Die erste Phase war von einer spannungsvollen Diskrepanz zwischen hochfliegenden Plänen und enttäuschender Realität geprägt. Fischers eingangs zitierte Rede vom Januar $1999^{8}$ war nur der Auftakt für eine Debatte, wie sie die europäische Integration noch nicht gesehen hatte. Wer Rang und Namen hatte in der europäischen Politik trug in den folgenden zweieinhalb Jahren sein Leitbild eines zu Ende gedachten Europas ${ }^{9}$ vor. Neu daran war nicht in erster Linie die Substanz der Entwürfe - so etwas war seit der Nachkriegszeit in der Europäischen Bewegung, in akademischen Kreisen und auch von weise gewordenen, ehemaligen Spitzenpolitikern erwogen worden ${ }^{10}$-, sondern die Tatsache, dass es amtierende, in der Verantwortung stehende Inhaber höchster Ämter waren, die das Wort ergriffen, also Funktionsträger, die man (noch) beim Wort nehmen, denen man die Umsetzung ihrer Pläne zumuten (wenn nicht zutrauen) konnte.

Das „Zweite Schäuble-Lamers-Papier“ vom Mai $1999^{11}$ enthielt bereits die Vorstellung eines Verfassungsvertrags, der der Europäischen Union einen Wettbewerbsföderalismus ins Stammbuch schreiben sollte, mit föderaler Währungs- und Wirtschaftsverfassung, konkurrierenden Sozialsystemen und einem hohen Integrationsstand für die Außen- und Sicherheitspolitik. Bescheidenere, aber immer noch weitreichende Reformvorschläge wurden im Auftrag der Europäischen Kommission im Herbst 1999 von „Drei Weisen“ - Richard von Weizsäcker, Jean-Luc Dehaene, David Simon - vorgetragen, insbesondere im Hinblick auf die Osterweiterung. ${ }^{12}$ Johannes Rau, als deutscher Bundespräsident, griff mit vehementen Plädoyers für eine europäische Verfassung in die öffentliche Debatte ein ${ }^{13}$ und machte damit endgültig den Verfassungsbegriff im europapolitischen Milieu hoffähig. Der frühere Kommissionspräsident Jacques Delors meldete sich mit seiner Idee einer „Föderation der Nationalstaaten “, vorab zu verwirklichen durch eine Avantgarde, im Frühjahr 2000 zu Wort ${ }^{14}$ und versuchte damit eine Art Quadratur des Kreises: Europäische Föderation und fortbestehende Souveränität der Staaten sind nicht leicht zusammen zu denken. Von vielen Beobachtern wurde Fischers Rede zum 50. Jahrestag des Schuman-Plans, am 12. Mai 2000, unter dem Titel ,Vom Staatenverbund zur Föderation - Gedanken über die Finalität der europäischen In-

8 Fischer: Rede des Vorsitzenden des Rates der Europäischen Union, 2001.

9 „Finalität“ ist der in dieser Zeit am meisten benutzte Begriff für das „,zu Ende Denken“. Vgl. als Beispiel die „Kolloquienreihe zur ,Finalität Europas““ des Wissenschaftszentrums Berlin in dieser Zeit. Eine Übersicht ist abrufbar unter: http://www.wiko-berlin.de/index.php?id=180 (letzter Zugriff: 23.01.2011). Zum älteren Begriff „Leitbild“ vgl. dagegen Heinrich Schneider: Leitbilder der Europapolitik I: Der Weg zur Integration, Bonn 1986.

10 Loth: Entwürfe einer europäischen Verfassung, 2002; Lipgens: 45 Jahre Ringen um die Europäische Verfassung, 1986.

11 Lamers/Schäuble: Europa braucht einen Verfassungsvertrag, 2001.

12 Jean-Luc Dehaene/David Simon/Richard von Weizsäcker: Die institutionellen Auswirkungen der Erweiterung. Bericht an die Europäische Kommission (18. Oktober 1999), abgedruckt in: Wilfried Loth: Entwürfe einer europäischen Verfassung. Eine historische Bilanz, Bonn 2002, S. 227-240.

13 Vgl. Johannes Rau: Die Quelle der Legitimation deutlich machen. Eine föderale Verfassung für Europa, in: Frankfurter Allgemeine Zeitung, 04.11.1999 sowie das „Plädoyer für eine Europäische Verfassung“, Johannes Rau: Rede vor dem Europäischen Parlament, 4. April 2000, mit weiteren Texten abgedruckt in Hartmut Marhold: Die neue Europadebatte, 2. Auflage, Bonn 2002, S. $90 \mathrm{ff}$.

14 Vgl. Le Monde: Interview mit Jacques Delors, 19.01.2000; besondere Aufmerksamkeit verdient Delors' Rede zum 50. Jahrestag des Schuman-Plans (also die Parallele zu Fischers viel weiter verbreiteter, drei Tage später gehaltener Rede) unter dem Titel „Le pardon et la promesse. L’héritage vivant de Robert Schuman“. Vgl. Notre Europe: „Le pardon et la promesse. L'héritage vivant de Robert Schuman“, Commémoration du cinquantenaire de la Déclaration Schuman Luxembourg, 9 mai 2000, 03.05.2000. 
tegration“" 15 für den Höhepunkt (von manchen gar für den Auftakt) der Debatte gehalten. In der Tat gab es in der Integrationsgeschichte wenige Reden aktiver Politiker, die weiter über den jeweils erreichten Integrationsstand hinauswiesen. Verfassung und Föderation waren solche Leitbegriffe für die Zukunft, aber andererseits hatte Fischer sich sorgfältig mit französischen Positionen beschäftigt und Angebote an die französische Seite in seine Rede eingearbeitet - so etwa eine herausgehobene Rolle für die nationalen Parlamente -, um seine Initiative gleich auf eine deutsch-französische Basis gründen zu können, möglicherweise der Kern des ,Gravitationszentrums', das auf diesem Weg vorangehen sollte. Umso überraschender waren die französischen Reaktionen: Jean-Pierre Chevènement, sozialistischer Innenminister und einer der Gralshüter französischen Souveränitätsdenkens, warf Fischer vor, den Nationalsozialismus noch nicht ganz verdaut zu haben und dessen Austreibung gleich durch die Absage an nationale Identität maßlos übersteigert zu haben - eine als skandalös eingeschätzte Ablehnung, die Fischer und Chevènement in eine länger dauernde Kontroverse führte. ${ }^{16}$ Der französische Staatspräsident Jacques Chirac gab die Antwort auf Fischer in seiner Rede vor dem Deutschen Bundestag am 28. Juni 2000, ${ }^{17}$ in der erstmals ein französischer Staatschef eine europäische „Verfassung“ empfahl, allerdings auch zunächst nur für eine „Pioniergruppe“ - eine erstaunliche Wende für das gaullistische politische Denken in Frankreich. Tony Blair mischte sich im Herbst 2000 in die Debatte ein, ${ }^{18}$ seine Botschaft wird schon durch die Wahl des Ortes deutlich, an dem er die Rede hielt - in der Börse in Warschau, was heißen sollte: Erweiterung geht über Vertiefung und die Europäische Union ist vorwiegend eine wirtschaftliche, erst in zweiter Linie eine politische Union. So auch der Inhalt der Rede: Großbritannien solle mit seiner traditionellen Europapolitik brechen, versprach Blair, sein Land werde nicht mehr eine ,Wait-and-see'-Haltung einnehmen, sondern selbst den Integrationsprozess vorantreiben - allerdings in eine Richtung, die den britischen Vorstellungen entspricht, und das heißt zum Beispiel im Hinblick auf eventuelle Verfassungsideen eine Orientierung auf das britische Modell, in dem es ein geschriebenes Verfassungsdokument bekanntlich nicht gibt, ohne dass dadurch die demokratische Qualität des britischen Staatswesens beeinträchtig wäre. In dem konservativen spanischen Ministerpräsidenten José María Aznar fand Blair einen Alliierten, gemeinsam mit ihm führte er seine Kampagne weiter. Auch noch im folgenden Jahr 2001 setzte sich der Diskurs fort, insbesondere mit zwei Beiträgern, deren Abwesenheit inzwischen auffiel, dem französischen Premierminister Lionel Jospin, der sich mit Nuancierungen der Konzeption einer Föderation der Nationalstaaten anschloss, ${ }^{19}$ und dem deutschen Bundeskanzler Gerhard Schröder, dem ein SPD-Papier unter dem Titel „Verantwortung für Europa“20 ${ }^{20}$ zugeschrieben wurde, in dem das europäische Sozialmodell an erster Stelle steht und die institutionelle Fortentwicklung

15 Joschka Fischer: Vom Staatenverbund zur Föderation - Gedanken über die Finalität der europäischen Integration, abgedruckt in: integration 3/2000, S. 149-156.

16 Die Kontroverse ist dokumentiert in Marhold: Die neue Europadebatte, 2. Auflage, 2002, S. 186ff.

17 Jacques Chirac: „Notre Europe - Unser Europa“. Rede vor dem Deutschen Bundestag, Berlin, 27. Juni 2000, abgedruckt in: Konrad-Adenauer-Stiftung (Hrsg.): Europäische Grundsatzreden 1946-2006, abrufbar unter: http://www.kas.de/wf/doc/kas_9186-544-1-30.pdf (letzter Zugriff: 23.01.2011).

18 Tony Blair: Rede des britischen Premierministers am 6. Oktober 2000 in Warschau: „Europas politische Zukunft", abgedruckt in: Wilfried Loth: Entwürfe einer europäischen Verfassung. Eine historische Bilanz, Bonn 2002, S. 253-265.

19 Lionel Jospin: Rede des französischen Premierministers zur „Zukunft des erweiterten Europas“ am 28. Mai 2001, abgedruckt in: Wilfried Loth: Entwürfe einer europäischen Verfassung. Eine historische Bilanz, Bonn 2002, S. 285-299.

20 Sozialdemokratische Partei Deutschlands: Leitantrag „Verantwortung für Europa“ für den SPD-Bundesparteitag in Nürnberg vom 19.-23. November 2001. Entwurf (Stand: 30.04.2001), abgedruckt in: Wilfried Loth: Entwürfe einer europäischen Verfassung. Eine historische Bilanz, Bonn 2002, S. 267-284. 
wesentlich deutschen Erfahrungen mit dem Föderalismus entspricht. Auch aus Ostmitteleuropa war schon eine Stimme zu hören, vielleicht nicht zufällig - angesichts tief verwurzelter Verfassungstraditionen - aus Polen, von dessen damaligem Außenminister Władysław Bartoszewski, ${ }^{21}$ der seinerseits eine europäische Verfassungsbildung favorisierte. Und all dies ist nur ein Schnelldurchgang durch eine überaus gedankenreiche und - im wahrsten Sinne des Wortes - viel versprechende Debatte, die über zwei Jahre angedauert hat.

Lässt man die überaus vielfältigen Ideen und Visionen Revue passieren, 22 zeichnen sich fünf große Motive für eine grundlegende Reform ab: Zunächst wurde schon lange ein immer zäheres Funktionieren der alten Mechanismen der Europäischen Union beklagt - waren die Institutionen, geschaffen für wenige konkrete Politikfelder und sechs Mitgliedstaaten, nicht längst anpassungsbedürftig? Zweitens würde die schon jetzt festzustellende sinkende Effizienz des Systems nach einer Erweiterung auf nahezu doppelt so viele Mitgliedstaaten wahrscheinlich die Europäische Union entscheidungsunfähig machen. Und drittens geschah dies ausgerechnet in einer Zeit, in der Europa in einer sich rapide global vernetzenden Welt seine Identität aktiv wahren, international handlungsfähig werden und als Akteur der Weltpolitik viel größere Entscheidungskapazität aufbauen sollte. Viertens schien der Moment gekommen, die Früchte eines langen Integrationsprozesses tatsächlich zu ernten, da doch die wirtschafts- und währungspolitische Integration mit der Währungsunion ihr Ziel erreicht hatte. Und, last not least, musste die Europäische Union das Problem ernst nehmen, dass immer mehr Bürger nichts von ihr hielten, während sie doch immer mehr in die Rolle eines voll ausgebauten politischen Systems, mit staatsähnlichen Merkmalen, hineinwuchs - die Europäische Union sollte eine supranationale Demokratie werden.

\section{In den Niederungen der integrationspolitischen Wirklichkeit}

Auf der anderen Seite allerdings quälte sich der reale Integrationsprozess auf ausgetretenen Pfaden zu enttäuschenden Ergebnissen. Der Vertrag von Nizza wurde von einer Regierungskonferenz vorbereitet, die nahezu das gesamte Jahr 2000 in Anspruch nahm, wie üblich in vielen Verhandlungsrunden unter mandatsgebundenen Diplomaten, denen es per definitionem unmöglich ist, die großen Sprünge ihrer Chefs nachzuvollziehen. ${ }^{23}$ In Nizza kam es folglich und unvermeidlich zum großen Tauziehen um kleinliche, vermeintliche nationale Vor- und Nachteile, zugespitzt auf die Frage der Stimmengewichtung bei Mehrheitsabstimmungen im Rat. Während das Konzept der ,doppelten Mehrheit', bestehend aus einer Mehrheit der Mitgliedstaaten sowie einer Mehrheit der Bevölkerung, bereits zur Disposition stand, blieb das Prinzip der gewichteten Stimmen noch im Rennen. Besonders Frankreich konnte sich nicht dazu durchringen, die allein in der Stimmengewichtung noch bewahrte Parität mit dem demografisch gewichtigeren Deutschland aufzugeben. Frankreich, das hieß angesichts baldiger Präsidentschaftswahlen, dass sich weder der amtierende gaullistische Präsident Chirac noch der sozialistische Kandidat Jospin vorwerfen lassen wollten, eine französische Grundposition aufgegeben zu haben, sodass die französische Ratspräsidentschaft nicht kompromissfähig war. Sage und schreibe fünf Tage und Nächte dauerten die Verhandlungen, bis zur physischen Erschöpfung der Beteiligten, die dann an einem Montagmorgen - eigentlich hatte die Regierungskonferenz am Freitag enden sollen - bekannt ga-

21 Bartoszewski: ,in: Marhold: Die neue Europadebatte, 2. Auflage, Bonn 2002, S. 420.

22 Eine zusammenfassende Analyse in der Einleitung zu Marhold: Die neue Europadebatte, 2. Auflage, Bonn 2002, S. $9 \mathrm{ff}$.

23 Zur Regierungskonferenz 2000 vgl. die Analysen in Edward Best/Mark Gray/Alexander Stubb (Hrsg.): Rethinking the European Union: IGC 2000 and Beyond, Maastricht 2000. 
ben, dass sie das neue System der doppelten Mehrheit einführen - aber zugleich das alte System der Stimmengewichtung beibehalten! Dies ist das mit Abstand komplizierteste Entscheidungsverfahren seit Integrationsbeginn. Und mehr noch: Da Frankreich trotz der demografischen Distanz zu Deutschland auf Parität bei der Stimmengewichtung bestand, wurden auch Spanien und Polen hellhörig und setzten durch, dass sie nur zwei Stimmen weniger (27 statt 29) erhielten, da doch ihre Bevölkerungszahlen auch nicht weiter von der Frankreichs entfernt sind als die französische von der deutschen. Eine Absurdität zieht die nächste nach sich: Auf diese für Spanien und Polen besonders ,vorteilhafte' Gewichtung gründete sich später hauptsächlich der polnisch-spanische Widerstand gegen den Verfassungsvertrag, der nur noch die doppelte Mehrheit ohne Stimmengewichtung vorsah.

Obwohl der Vertrag von Nizza das Mitentscheidungsverfahren auf einige weitere Politikbereiche ausweitete (zum Beispiel die Innen- und Justizpolitik) und bestimmte formale Bedingungen für die große Erweiterung nach Ostmitteleuropa schuf ${ }^{24}$ war doch nicht zu leugnen, dass von einer großen Systemreform keine Rede sein konnte, zumal dann nicht, wenn man den Maßstab der gleichzeitigen Leitbild-Debatte anlegte. Die Entscheidungsverfahren waren noch schwieriger geworden, die Funktionsfähigkeit der Union dadurch keineswegs gestärkt, womöglich sogar geschwächt. Von mehr Transparenz, Verständlichkeit und Bürgernähe konnte keine Rede sein. Die Außen-, Sicherheits- und Verteidigungspolitik blieb weiterhin intergouvernementalen Prozeduren unterworfen, einer politischen Union kam die Europäische Union nicht näher. Und über die schon an sich enttäuschenden konkreten Ergebnisse hinaus war noch bedenklicher, dass eine große Zahl der Regierungsvertreter in Blockademöglichkeiten raisonnierte, um mögliche unliebsame EU-Entscheidungen verhindern zu können, wo es doch eigentlich darum gehen sollte, umgekehrt die Europäische Union entscheidungsfähiger und -freudiger zu machen. Die Diskrepanz zwischen den Entwürfen und der Realität war flagrant und schwer auszuhalten. Das war auch den Staats- und Regierungschefs noch in Nizza selbst klar geworden und sie waren selbstkritisch genug, den Schlussfolgerungen eine „Erklärung“ 25 anzufügen, in der sie weitergehende Reformen in Aussicht nahmen, schon mit vier identifizierbaren Aufgabenfeldern: Die Kompetenzverteilung zwischen den Mitgliedstaaten und der Europäischen Union sollte deutlicher, der Charta der Grundrechte der Europäischen Union ein eindeutiger Status zugewiesen, die nationalen Parlamente in das Ensemble von europapolitischen Akteuren eingebunden und die Verträge insgesamt vereinfacht werden. ${ }^{26}$

\section{Von Nizza nach Laeken: auf dem Weg zur neuen Reformmethode}

Das Jahr 2001 war eine Scharnierphase in der zehnjährigen Geschichte des Reformprozesses. In dieser Zeit fiel die Entscheidung für eine neue Art der Systemreform. Die Forderung nach einer anderen Methode für die nächste Vertragsrevision wurde sehr schnell erhoben und in der Tat konzentrierte sich die Debatte im Jahr 2001 auf die Methode, nicht auf die Inhalte einer weiteren Reformrunde. Dafür war zum einen das offensichtlich irrationale und in Nizza ad absurdum geführte Verfahren tage- und nächtelanger Verhandlungen zwischen den Staats- und Regierungschefs maßgeblich. Es schien nicht tauglich zu sein, um der Europäischen Union einen qualitativen Sprung in eine neue Ära der Integration zu ermögli-

24 So wurde beispielsweise die Zahl von Sitzen für die absehbaren neuen Mitgliedstaaten im Europäischen Parlament festgelegt und die Verkleinerung der Kommission durch den Verzicht der großen Mitgliedstaaten auf einen zweiten Kommissar beschlossen.

25 23. Erklärung zur Zukunft der Union zum Vertrag von Nizza, in: Amtsblatt der EU, Nr. C 80 vom 10. März 2001, S. 85. Zu Analysen der Erklärung vgl. Mathias Jopp/Barbara Lippert/Heinrich Schneider (Hrsg.): Das Vertragswerk von Nizza und die Zukunft der Europäischen Union, Bonn 2001.

26 Zu Einzelaspekten und zur Gesamtbewertung des Vertrags von Nizza vgl. ebenda. 
chen. Und auf der anderen Seite stand eine alternative Methode zur Anwendung bereit: Zwischen Herbst 1999 und Oktober 2000 hatte ein Konvent, bestehend aus Abgeordneten und Regierungsvertretern, unter der Leitung des früheren deutschen Bundespräsidenten Roman Herzog mit großem Erfolg eine europäische Grundrechtecharta ${ }^{27}$ erarbeitet und damit bewiesen, dass diese Methode zu greifbaren Ergebnissen führen konnte. Anfang 2001 sah es also so aus, als habe die eine Methode ausgedient, während die alternative erfolgreich war. Nichts lag näher, als diese neue Methode auch für die Aufgabe einer kompletten Vertragsreform, ja Verfassungsbildung zu verwenden.

Die europäischen Parteienzusammenschlüsse erhoben diese Forderung bereits im Frühjahr ${ }^{28}$ nicht nur wegen des Erfolges der Konventsmethode, sondern auch wegen ihres demokratischeren Charakters, wegen der Beteiligung von Parlamenten - nicht nur Effizienzgesichtspunkte, auch demokratietheoretische Argumente spielten also eine Rolle. Das Europäische Parlament schloss sich bald den Vordenkern an, kritisierte heftig die Methoden, die zum Vertrag zu Nizza geführt hatten und drängte auf eine ,radikale Alternative“. ${ }^{29}$ Die Staats- und Regierungschefs hatten natürlicherweise mehr Bedenken, eine so radikale Wende in der Reformmethode zu vollziehen, hätte sie doch ihre eigene Marginalisierung bedeutet. Zur Jahresmitte standen sich weiterhin Forderung und Zögern gegenüber, die Entscheidung war noch nicht gefallen, die Schlussfolgerungen des Europäischen Rates unter schwedischer Ratspräsidentschaft sprachen noch von der ,etwaigen Schaffung eines offenen Forums “ für die nächste Reformrunde. ${ }^{30}$ Erst im Herbst 2001, unter belgischer, sehr integrationsfreundlicher Ratspräsidentschaft, erfüllte der (informelle) Europäische Rat die Forderung endgültig ${ }^{31}$ und entschloss sich, den Auftrag zu einer grundlegenden Überholung der

27 Charta der Grundrechte der Europäischen Union, in: Amtsblatt der Europäischen Union, Nr. C 83 vom 30. März 2010, S. 389-403. Vgl. auch die Beiträge von Jo Leinen/Justus Schönlau: Die Erarbeitung der EUGrundrechtecharta im Konvent: nützliche Erfahrungen für die Zukunft Europas, in: integration 1/2001, S. 26-33; Wolfgang Dix: Grundrechtecharta und Konvent - auf neuen Wegen zur reform der EU?, in: integration 1/2001, S. 34-41; Ingolf Pernice: Der Post-Nizza-Prozess. Auf dem Weg zu einer neuen europäischen Verfassung?, in: integration 2/2001, S. 194-197.

28 Die EVP-Fraktion brachte bereits am 12. Januar 2001 einen Antrag im Europäischen Parlament ein, in dem sie „,neue Wege der Entscheidungsvorbereitung [fordert], z.B. eine Konferenz basierend auf dem erfolgreichen Modell des Konvents zur Vorbereitung der Grundrechtscharta“. EVP-ED-Fraktion im Europäischen Parlament: Post-Nizza Entschließungsantrag, angenommen vom XIV. EVP-Kongreß, 11.-13. Januar 2001, Berlin, abrufbar unter: http://epp-ed.europarl.eu.int/press/peve00/eve015res05_de.asp (letzter Zugriff: 24.01.2011). Die SPE führte unter anderem seit Anfang Mai 2001 Gespräche mit Politikern aller Mitgliedstaaten, um „,die Idee der SPE-Fraktion zu verbreiten, eine ,Konvention“ zu schaffen, die die Vertreter der Mitgliedstaaten und der nationalen und europäischen Parlamente sowie die der Kommission zusammenbringt, um die nächste Regierungskonferenz 2004 vorzubereiten“.

29 Vgl. zum Beispiel den de Vigo-Seguro-Bericht des Konstitutionellen Ausschusses vom 4. Mai 2001, in dem es unter anderem heißt, das Europäische Parlament, insists that the holding of a new IGC should be based on a radically different process which is transparent and open to participation by the European Parliament, the national parliaments and the Commission and which involves the citizens of the Member States and the applicant countries, as provided for in Declaration 23, and that the new IGC should initiate a constitutional development process." Europäisches Parlament, Ausschuss für konstitutionelle Fragen: Report on the Treaty of Nice and the future of the European Union, Berichterstatter: Iñigo Méndez de Vigo/António José Seguro, A5-0168/2001. Entscheidend für die Haltung des Parlaments war dann der Leinen-de Vigo-Bericht vom 23. Oktober 2001, der erstmals am 13. September im Konstitutionellen Ausschuss diskutiert und demzufolge vermutlich vor den Terroranschlägen des 11. Septembers fertig gestellt worden ist.

30 Europäischer Rat: Schlussfolgerungen des Vorsitzes. Europäischer Rat (Göteborg) 15. und 16. Juni 2001, SN 200/1/01

31 Vgl. den Kommentar des Europäischen Parlaments dazu: Das Europäische Parlament „bringt seine Genugtuung über den Erfolg des Eintretens der belgischen Präsidentschaft für den Gedanken eines Konvents und eines entsprechenden Zeitplans zum Ausdruck." Europäisches Parlament: Gemeinsamer Entschließungsantrag. Entschließung des Europäischen Parlaments zu den Ergebnissen der informellen Tagung des Europäischen Rates vom 19. Oktober 2001 in Gent, 23.10.2001, B5-0696/2001, B5-0697/2001, B5-0698/2001, B5-0700/2001. 
bestehenden Verträge einem Konvent zu überantworten - allerdings mit Leitplanken, die dem Europäischen Rat doch noch das letzte Wort einräumten: Erstens wurde der Konvent mit einem Mandat des Rates beauftragt, war also nicht völlig frei in seiner Aufgabenstellung. Und zeitens sollte das Resultat des Konvents den Staats- und Regierungschefs zur Billigung, gegebenenfalls zur Modifikation, vorgelegt werden, bevor es in die Ratifizierung gehen sollte.

Die Frage, inwieweit die Terroranschläge des 11. September 2001 den ,Post-Nizza-Prozess' auf dem Weg nach ,Laeken ' beeinflusst haben, lässt sich wohl kaum eindeutig beantworten. Die Sondertagung des Europäischen Rates vom 21. September 2001 galt zwar den Konsequenzen aus dem ,11. September', stellte aber die Verbindung zwischen internationalem Terrorismus und EU-Reform nicht her. Einen eindeutigen Bezug auf die Terroranschläge des 11. September 2001 gibt es wohl (in offiziellen Dokumenten) nur in der deutsch-französischen Erklärung vom 10. Dezember 2001.“32

Immerhin war das am 15. Dezember 2001 beschlossene Mandat von Laeken ${ }^{33}$ unerwartet weitherzig abgefasst und ließ dem Konvent sehr großen Spielraum: Über sechzig teilweise grundlegende Fragen, die an die „Erklärung zur Zukunft der Union“ von Nizza anknüpften und deren Programm noch einmal in Richtung Demokratisierung und Transparenz erweiterten, sollten zu neuen Antworten führen und selbst der Verfassungsbegriff wurde nicht länger tabuisiert. Damit war die Entscheidung für den Aufbruch in eine andere Europäische Union gefallen, freilich immer noch unter dem Vorbehalt einer an- und abschließenden Akzeptanz durch die Regierungen. Es handelte sich nicht um eine Konstituante, der Konvent sollte und konnte nach seinem Zustandekommen und seiner Zusammensetzung keine verfassunggebende Versammlung werden. Denn auch über die Zusammensetzung hatten die Staats- und Regierungschefs selbst entschieden: Aus allen damals 28 Mitglieds- und Kandidatenstaaten, das heißt inklusive der Türkei, sollten je zwei Parlamentsabgeordnete in den Konvent entsandt werden, zusätzlich 16 Abgeordnete des Europäischen Parlaments, je ein Vertreter aller beteiligten Staaten, zwei Vertreter der Europäischen Kommission und ein Präsident, assistiert von zwei Vizepräsidenten - letztere drei ernannte der Europäische Rat namentlich und entschied sich dabei für Valéry Giscard d'Estaing, den früheren französischen Staatspräsidenten, als Präsidenten. Damit war auch einer der ihren, ein früheres Mitglied, ja der Begründer des Europäischen Rates, zum Vorsitzenden des Konvents bestimmt worden.

\section{Der Konvent (Februar 2002 bis Sommer 2003)}

Am 28. Februar 2002 eröffnete Giscard d'Estaing die Sitzungen des Konvents, ${ }^{34}$ die die nächsten eineinhalb Jahre in Anspruch nahmen und wohl den Kulminationspunkt des Abschnitts europäischer Integrationsgeschichte bilden, ${ }^{35}$ der hier nachzuzeichnen ist. Schon in

32 In der Erklärung heißt es: „,Vor dem Hintergrund der Terroranschläge in den Vereinigten Staaten vom 11. September wird immer deutlicher, dass Europa heute vor einer neuen Herausforderung steht. Daher ist eine Vertiefung der Integration in dem Bereich der GASP/ESVP sowie bei der Schaffung des Raums des Rechts, der Freiheit und der Sicherheit dringend notwendig. Dies kann zugleich zu einer neuen Antriebskraft im europäischen Integrationsprozess werden." Vgl. Deutsch-französisches Treffen über die Zukunft der europäischen Union, Gemeinsame Entschließung an den Europäischen Rat von Laeken, Paris, 10. Dezember 2001, abrufbar unter http://www.assemblee-nationale.fr/europe/themes/rencontres.asp (letzter Zugriff: 17.01.2011).

33 Erklärung von Laeken zur Zukunft der Europäischen Union, in: Europäischer Rat: Schlussfolgerungen des Vorsitzes. Europäischer Rat (Laeken) 14. und 15. Dezember 2001, SN 300/1/01, S. 19-26.

34 Valéry Giscard d'Estaing: Eröffnungsrede vor dem Konvent zur Zukunft Europas, 26.02.2002, Konventsdokument SN 1565/02.

35 Das gilt auch für die Fülle der kommentierenden politischen und wissenschaftlichen Literatur zum Konvent und desgleichen für die Veröffentlichungen des Konvents selbst, auf dessen Homepage. Wo die im Folgenden 
seiner Eröffnungsrede entschied Giscard d'Estaing, dass der Konvent sein Mandat bis an dessen Grenzen ausschöpfen und die weitreichendste Variante verschiedener Möglichkeiten wählen sollte. Nicht nur Optionen sollte das neue Gremium den Staats- und Regierungschefs vorlegen (über die diese dann in der altgewohnten Weise streiten würden), sondern einen einzigen kohärenten Vertrags- oder Verfassungstext; und dieser Text sollte im Konsens verabschiedet werden, das heißt ohne Alternativen und Spaltungen.

Unter diesen überaus ambitionierten Vorgaben entfaltete der Konvent eine Dynamik, die in drei Phasen gegliedert war: Die ersten Monate, bis zum Sommer 2002, sollten dem Zuhören dienen, der Aufnahme von Erwartungen, Forderungen, Befürchtungen und Hoffnungen aus den Mitgliedstaaten, aus der Bevölkerung. Im darauffolgenden Halbjahr, von Mitte bis Ende 2002, beschäftigten sich Arbeitsgruppen mit einzelnen Politikfeldern und Themenkreisen, die reformbedürftig erschienen und letztlich das gesamte Themenspektrum europäischer Politik abdeckten. Obwohl die Arbeitsgruppen zumeist mit ,policies' zu tun hatten, trat schon um diese Zeit die Frage nach der institutionellen Gestalt der reformierten Union in den Vordergrund des Interesses, insbesondere die Rollen der Institutionen, die als Ausdruck des intergouvernementalen Charakters einerseits und des supranationalen, föderalen Integrationskonzepts andererseits gelten. Die Rolle des Europäischen Rates, die Aufgaben und Zusammensetzung der Kommission, das Verhältnis beider zueinander und die Stärkung des Parlaments, vor allem bei der ,Regierungsbildung', wurden kontrovers diskutiert. Der Lösung dieser Fragen widmete sich der Konvent allerdings erst im dritten Teilabschnitt seiner Debatten, ab Januar 2003, obwohl nicht wenige Konventsmitglieder längst ungeduldig geworden waren, eigene Verfassungsentwürfe schon ab Herbst 2002 vorlegten, ${ }^{36}$ ja mit dem ganzen Vorgehen nicht einverstanden waren, sondern es lieber gesehen hätten, wenn sehr schnell ein Textentwurf vorgelegen hätte, den man dann ausführlich hätte diskutieren und nuancieren können. Aber die interne Dynamik des Konvents war auch von dem Gegenüber zwischen dem steuernden, zurückhaltenden, behutsamen zwölfköpfigen Präsidium und dem parlamentarisch dominierten, vorwärts drängenden Plenum geprägt, wobei sich, nicht zuletzt dank der starken Persönlichkeit Giscard d'Estaings, das Präsidium oft durchsetzte, jedenfalls hinsichtlich der Verfahren.

Inzwischen hatte sich indessen die Auffassung durchgesetzt, dass das Ergebnis der ganzen Mühen tatsächlich ein Verfassungsvertrag sein sollte - der Durchbruch auf diesem

zusammengefassten Entwicklungen im Einzelnen weiterhin nachzuvollziehen sind. Die Internetseite des Europäischen Konvents ist abrufbar unter: http://european-convention.eu.int/bienvenue.asp?lang=de (letzter Zugriff: 31.01.2011). Aus der Vielfalt der Literatur: Werner Weidenfeld (unter Mitarbeit von Janis Emmanouilidis/Almut Metz/Sibylle Reiter): Die Europäische Verfassung verstehen, Gütersloh 2006; Lenka Rovná/Wolfgang Wessels (Hrsg.): EU Constitutionalisation: From the Convention to the Constitutional Treaty 2002-2005. Anatomy, Analysis, Assessment, Prag 2006. Vgl. auch die Beiträge in dem ausschließlich dem Konvent gewidmeten integration. Heinrich Schneider (Hrsg.): Der Verfassungsentwurf des Europäischen Konvents, integration 4/2003.

36 Vgl. etwa Europäischer Konvent: Beitrag des Mitglieds des Konvents Herrn Andrew Duff: „Ein Verfassungsmodell für eine Föderale Europäische Union“, Konventsdokument CONV 234/02. Der deutsche Europa-Abgeordnete Elmar Brok, der für das Europäische Parlament Mitglied im Konvent war, legte ein etwas behutsameres , discussion paper" vor. Vgl. Europäischer Konvent: Beitrag des Mitglieds des Konvents Herrn Brok - „Verfassung der Europäischen Union“, CONV 325/02; der deutsche Vorsitzende des Konstitutionellen Ausschusses im Europäischen Parlament Jo Leinen: Draft Constitution of the European Union. Proposal to the "Convention on the Future of Europe”, 24.10.2002; der österreichische Grüne Johannes Voggenhuber; vgl. Europäischer Konvent: Beitrag vorgestellt von Herrn Johannes Voggenhuber, Mitglied des Konvents: „Die Einheit Europas“, CONV 499/03; auch die Europäische Kommission mischte sich mit einem (wenig erfolgreichen) Verfassungsentwurf unter dem Namen „Penelope“ in die Debatte ein. Kommission der Europäischen Gemeinschaften: Feasibility Study (,Penelope-Entwurf'), abgedruckt in: Heinz Kleger (Hrsg.): Der Konvent als Labor. Texte und Dokumente zum europäischen Verfassungsprozeß, 2. Auflage, Münster/Hamburg/London, S. 463-650. 
Wege war die Bereitschaft des Vereinigten Königreichs, den Verfassungsbegriff für das Dokument zu akzeptieren. Jack Straw, als Außenminister, stellte in einer Rede vor der schottischen Handelskammer im August 2002 die britische Ampel auf Grün, ${ }^{37}$ in der er dem Verfassungsbegriff weiter keinen Widerstand mehr entgegensetzte, aber zugleich keinen Zweifel an der britischen Definition der Aufgaben einer solchen europäischen Verfassung ließ: Sie sollte nämlich in erster Linie die Souveränität der Mitgliedstaaten ein für allemal festschreiben. Auch wenn darin eine contradictio in adjecto gelegen haben mag, der Wandel der britischen Position im Vergleich zu Blairs Rede zwei Jahre zuvor war flagrant und machte den Weg zum Konsens über den Begriff Verfassungsvertrag frei, da von anderen, auch den ostmitteleuropäischen Kandidatenstaaten, kein ernsthafterer Widerstand als der britische zum Ausdruck gebracht wurde.

Es war denn auch das Präsidium, das dem Plenum ab Januar 2003 kapitelweise Artikel für den zukünftigen Vertrag vorschlug, die zum Teil heftig diskutiert wurden - die ersten sechzehn Artikel riefen, als sie im Januar 2003 vorgelegt wurden, knapp tausend Änderungsanträge hervor. Obwohl der Konvent in aller wünschenswerten Transparenz tagte, seine Sitzungen öffentlich abhielt, per Internet zugänglich machte, selbst die Protokolle der Arbeitsgruppensitzungen veröffentlichte und tatsächlich den radikalsten Forderungen nach Öffentlichkeit der Debatten nichts schuldig blieb, zeigt das Beispiel der tausend Änderungsanträge, dass für den nicht professionell mit diesen Dingen beschäftigten Bürger die Informationsflut beim besten Willen nicht zu bewältigen war. Auch die verdienstvolle Initiative des Konventssekretariats, diese tausend Alternativen auf rund hundert Seiten zusammenzufassen, ${ }^{38}$ verdeutlichte das Problem eher als es zu lösen. Und obwohl die Medien in vielen Ländern verhältnismäßig ausführlich über die Konventsarbeiten berichteten, blieb das Thema insgesamt in den Augen der europäischen Öffentlichkeit marginal. Ein allgemeines Interesse jedenfalls, das der Aufgabenstellung - eine europäische politische Gemeinschaft für das nächste halbe Jahrhundert zu schaffen - angemessen gewesen wäre, blieb aus. Ausgenommen von dem Übermaß an Mitteilungsbereitschaft des Konvents blieb übrigens das Präsidium, seine Sitzungen waren nicht öffentlich, die dort ausgetragenen Kontroversen wurden nur durch Berichte einzelner Mitglieder erkennbar.

Weder der zeitweilige Antagonismus zwischen Präsidium und Plenum noch das laue Interesse der großen Öffentlichkeit änderten indessen etwas daran, dass die Art der allmählichen Konsensbildung deliberativ, wenigstens deutlich deliberativer war als die früheren, durch Verhandlungen, durch das Ausspielen und Tauziehen um (vermeintliche) Interessen geprägten Regierungskonferenzen. Zwar kann auch im Konvent nicht von dem Idealfall die Rede sein, dass das beste Argument immer zur Durchsetzung kam, und Interessen sind zweifellos im Spiel gewesen. Aber die mindestens potenziell große und fast immer gewährleistete begrenzte Öffentlichkeit der Debatten sorgte dafür, dass Begründungen für Reformvorschläge sich auch durch Plausibilität und Vernünftigkeit auszeichnen mussten, um eine Chance zu haben. ${ }^{39}$

Für die Konturierung des politischen Systems jedenfalls war das Frühjahr 2003 die entscheidende Phase. Jetzt entschied sich eine Grundfrage, vor der die Reform gestanden hatte:

37 Jack Straw: Strength in Europe begins at home, Speech Edinburgh, 27.08.2002, abrufbar unter: http://www.futurum.gov.pl/d_eu/wyst/Jack_Straw.htm (letzter Zugriff: 31.01.2011).

38 Europäischer Konvent: Übermittlungsvermerk: Reaktionen auf den Entwurf der Artikel 1 bis 16 des Verfassungsvertrags - Übersichten. CONV 574/1/03. Das Dokument umfasst 109 Seiten.

39 Vgl. zu diese Frage Andreas Maurer: Die Methode des Konvents - ein Modell deliberativer Demokratie?, in: integration 2/2003, S. 130-140; Daniel Goeler: Deliberation - Ein Zukunftsmodell europäischer Entscheidungsfindung? Analyse der Beratungen des Verfassungskonvents 2002-2003, Baden-Baden 2006. 
Stand die Europäische Union, nach der (annähernden) Vollendung ihrer wirtschaftlichen Integration und vor der Schwelle zur politischen Gemeinschaftsbildung, nun vor der Wahl zwischen einem intergouvernementalen oder einem föderalen politischen System? Und auf welche Option würde die Wahl fallen? Die Frage wurde einmal mehr nicht beantwortet, die Entscheidung nicht getroffen - die Europäische Union des Verfassungsvertrags blieb ein politisches System doppelter Natur, mit intergouvernementalen und föderalen Zügen, mit einstimmigen Entscheidungsverfahren ganz in der Ägide der Mitgliedstaaten und ,ihrer' Unionsorgane (Ministerrat und Europäischer Rat) und mit Mehrheitsentscheidungen entsprechend der, Gemeinschaftsmethode', mit starker Implikation der supranationalen Institutionen Kommission und Parlament. Ein wegweisender Schritt auf dem Weg zur erneuerten Koexistenz beider Systemcharakteristika war der deutsch-französische Vorschlag ${ }^{40}$ zum Ensemble eines Europäischen Rates mit permanenter Präsidentschaft, eines Außenministers mit ,Doppelhut' und seiner Einbindung in die Europäische Kommission, vorgetragen anlässlich des 40. Jahrestages des Elysée-Vertrags im Januar 2003 und insofern voller historischer Symbolik im Spannungsfeld zwischen Integration und zwischenstaatlicher Zusammenarbeit. Die entscheidende Sitzung des Konventspräsidiums, in der diese Fragen geklärt wurden, fand im April 2003 statt. Nachdem Giscard d'Estaing seine Präsidiumskollegen am 23. April 2003 mit einem Vorschlag gereizt hatte, in dem er dem geplanten permanenten Präsidenten des Europäischen Rates ein gut ausgestattetes Sekretariat beigeben wollte (das sich möglicherweise zur Konkurrenz für die Europäische Kommission hätte auswachsen können) und seine Idee eines ständigen Gremiums der nationalen Parlamente auf europäischer Ebene erneuert hatte, revoltierte das Präsidium gegen diese Attacke auf die supranationalen europäischen Institutionen und einigte sich schließlich auf einen institutionellen Vorschlag, der die zu weit in die intergouvernementale Richtung gehenden Pläne Giscard d'Estaings wieder rückgängig machte, was das deutsche Präsidiumsmitglied Klaus Hänsch, früherer Präsident des Europäischen Parlaments, zu der Bemerkung veranlasste, man habe es mit dem seltenen Fall zu tun, dass ein gerupftes Huhn besser aussehe als zuvor. ${ }^{41}$

Inzwischen war der Irak-Krieg ausgebrochen und hatte eine externe Irritation in die Konventsberatungen hineingetragen, nach überaus schmerzhaften, ja bitteren Differenzen unter den Mitglied- und Kandidatenstaaten über die angemessene Reaktion auf die amerikanische Kriegsbereitschaft. Das Wort vom ,neuen Europa“ im Osten, das dem „alten Europa“ im Westen seinen Tatendrang entgegensetzte, war vom amerikanischen Verteidigungsminister Donald Rumsfeld in Umlauf gesetzt worden. Bundeskanzler Schröder und Staatspräsident Chirac hatten sich auf Widerstand gegen einen Krieg im Irak festgelegt und dafür auch noch mit Moskau eine Front gebildet, während Großbritannien, assistiert von Spanien und gefolgt von mehreren ostmitteleuropäischen Staaten, bereit war, den USA in den Irak zu folgen. ${ }^{42}$

Schließlich geriet der Konvent doch noch unter Zeitdruck, weil der Europäische Rat darauf bestand, dass das Ergebnis noch im Juni 2003 abzuliefern sei und jede Verlängerung über den Sommer hinaus, für die Giscard d'Estaing sich stark machte, kategorisch ablehnte. Das ursprüngliche Kalkül des Präsidenten, durch das Vorschalten zweier Phasen in der drit-

40 Mathias Jopp/Saskia Matl: Perspektiven der deutsch-französischen Konventsvorschläge für die institutionelle Architektur der Europäischen Union, in: integration 2/2003, S. 99-110; Text der deutsch-französischen Vorschläge: Bundeskanzleramt: Deutsch-französischer Beitrag zur institutionellen Architektur der Europäischen Union, Pressemitteilung Nr. 21, 15.01.2003.

41 Vgl. Frankfurter Allgemeine Zeitung: Konventspräsidium verändert GiscardsVorschläge stark, 25.04.2003.

42 Eine direkte Einwirkung des Irak-Krieges auf den Verfassungsbildungsprozess lässt sich zwar nicht nachweisen, siehe aber etwa, neben vielen anderen Beiträgen, Michel Barnier: Die Irak-Krise ist auch eine Chance für Europa, in: Frankfurter Allgemeine Zeitung, 26.02.2003. 
ten dann einen gesunden Druck Richtung Ergebnis zu erzeugen, wurde ironischerweise über das erhoffte Maß hinaus verstärkt, sodass der Konvent dem Europäischen Rat am 20. Juni 2003 ,nur' die ersten beiden Teile des geplanten Verfassungsvertrags vorlegen konnte und im Sommer ,nachsitzen' musste, um den doch so gehaltvollen dritten Teil fertig zu stellen, was endlich am 10. Juli 2003 gelang. Aber damit war dem Verfassungsvertrag eine Hypothek aufgebunden, die seiner Rationalität schadete. Er gliederte sich nun in drei Teile, einen durchaus lesbaren, rund fünfzig Seiten und annähernd ebenso viele Artikel umfassenden ersten mit den konstitutionellen Grundlagen, aber zugleich so vielen Verweisen auf den dritten Teil, dass man auch über grundlegende Verfassungsfragen - wie zum Beispiel das Mitentscheidungsverfahren - nur durch zusätzliche Lektüre des dritten Teils Aufschluss erhalten konnte. Hierhin, in den dritten, bei Weitem längsten Abschnitt des Verfassungsvertrags, floss nahezu die gesamte politische Substanz der bestehenden Verträge ein, die bei näherem Hinsehen nicht wesentlich verändert wurde. Das hatte auch die ohnehin schon sehr offensive Auslegung des Mandats von Laeken nicht hergegeben: Neue Kompetenzen, neue Politikfelder sollten der Union nicht übertragen, an der politischen Substanz höchstens Nuancierungen und Aktualisierungen vorgenommen werden. Ein neues Politikprojekt von der Art und dem Umfang etwa des Binnenmarktes oder der Währungsunion war von vornherein ausgeschlossen worden. Auch deshalb hatte sich die Debatte im Konvent, trotz der , policy '-orientierten Arbeitsgruppen, schon im Sommer 2002 auf Fragen des politischen Systems konzentriert. Der Verfassungsvertrag war eine Systemreform, kein Aufbruch zu neuen politikinhaltlichen Zielen der Integration.

Daraus entstand eine gewisse Fragwürdigkeit der Textkonstruktion, insofern der erste Teil des Verfassungsvertrags durchaus den demokratischen, an Grundwerten orientierten Reformelan des Konvents erkennen ließ, während der dritte Teil diesen Auf- und Ausbruchsversuch gewissermaßen dementierte durch die konservative Behandlung der politischen Kompetenzen und Aufgaben. Eine rationale Interpretation der späteren (allerdings oft irrationalen) Kritik am Verfassungsvertrag hat hier ihren Ursprung und setzt, polemisch überspitzt, an der Diskrepanz zwischen hoch gestimmten sozialen und humanistischen Wertbezügen und unverdrossen fortgesetzter Marktpolitik an. ${ }^{43}$ Zwischen beide Teile wurde, auch nicht unbedingt logisch, die Grundrechtecharta, als zweiter Teil des Verfassungsvertrags, eingeschoben. Immerhin, und das ist ein noch weit wichtigerer Grundzug des Verfassungsvertrags, wurden die bestehenden Verträge in ein einziges (wenn auch dreiteiliges) Dokument überführt. Erstmals seit Beginn der Vertragsentwicklung wurde nicht anund hinzugefügt, bei Fortbestehen der geltenden Texte, sondern alles in einen Text integriert. Und erstmals wurde damit eine Reduktion von Komplexität erreicht, während alle früheren Reformschritte zusätzliche Komplexität geschaffen hatten. Dass damit die Transparenz und Lesbarkeit der europäischen Grundordnung erhöht wurden, ist dem Konvent nicht abzustreiten - ob freilich die Komplexität des Vertragswerks soweit reduziert wurde, dass es nun auch für Bürger oder wenigstens für die Lehrer der Bürger in Schulen oder anderen pädagogischen Funktionen lesbar geworden wäre, bleibt mehr als zweifelhaft. Das Versprechen, einen Text zu schaffen, der es in seiner Verständlichkeit mit den großen Vorbildern früher nationalstaatlicher Verfassungen hätte aufnehmen können, konnte nicht eingelöst werden. Nicht zuletzt blieb schon im Begriff eine Ambiguität erhalten - handelte es sich denn letzten Endes um eine Verfassung oder um einen Vertrag?

43 Vgl. u.a. dazu Peter-Christian Müller-Graff: Systemrationalität in Kontinuität und Änderung des Europäischen Verfassungsvertrages, in: integration 4/2003, S. 301-316. 
Zweifellos hätte der Verfassungsvertrag die Grundlagen des europäischen politischen Systems saniert. Gesetz wurde ,Gesetz' genannt und nicht mehr Richtlinie - die Wahrhaftigkeit der Sprache wurde durchgesetzt, auch in anderen Fällen, wie dem des ,Außenministers ${ }^{6}$. Die Kompetenzaufteilung zwischen Mitgliedstaaten und Union wurde geklärt, ausschließliche Unionskompetenzen von konkurrierenden und unterstützenden getrennt. ${ }^{44}$ Die nationalen Parlamente wurden in die Entscheidungsfindung eingebunden, durch das Recht auf Einspruch gegen Unionsgesetzgebung, wenn diese dem Subsidiaritätsgebot widersprochen hätte, und durch Klagerecht vor dem Europäischen Gerichtshof. Wesentlich war die in Nizza so kläglich deformierte Reform des Entscheidungsverfahrens entsprechend der ,Gemeinschaftsmethode', das heißt die Einführung der doppelten Mehrheit ohne weitere Stimmgewichtung. Das Europäische Parlament wurde gestärkt, durch eine erneute Ausweitung des Mitentscheidungsverfahrens, durch eine politisch einsichtigere Mitsprache bei der Wahl des Kommissionspräsidenten und andere Maßnahmen. Die Kommission selbst zu reformieren war eine der schwierigsten Aufgaben, weil sie einerseits nicht länger mit der Mitgliederzahl der Union wachsen, andererseits nicht die Rückkoppelung an die Mitgliedstaaten und ihre politische Kultur verlieren durfte. ${ }^{45}$ Der Europäische Rat schließlich würde ein deutlicheres Profil erhalten durch die Permanenz der Präsidentschaft ebenso wie die Union als Ganze mindestens nach außen durch ihren neuen Außenminister klarer erkennbar geworden wäre das alles freilich ohne wirklich substanzielle neue Kompetenzen, ohne einen Durchbruch zu Mehrheitsentscheidungen etwa in der Außen-, Sicherheits- und Verteidigungspolitik. Schließlich hätte die Europäische Union die Rechtspersönlichkeit erhalten, die es ihr erlaubt hätte, auch formal als Akteur in der Weltpolitik aufzutreten. ${ }^{46}$

Die Berechtigung zum Feiern kann man dem Konvent nicht absprechen. Was Giscard d'Estaing im Februar 2002 angekündigt und was damals kaum jemand für realisierbar gehalten hatte, war Wirklichkeit geworden: Es lag ein einziges, kohärentes Dokument vor, das im Konsens verabschiedet worden war und mit Recht den Anspruch auf seinen Titel Verfassungsvertrag erheben konnte. Jetzt kam alles darauf an, was mit diesem Entwurf - denn um mehr handelte es sich ja noch nicht - geschehen würde..$^{47}$

\section{Das Schicksal des Verfassungsvertrags}

Der gescheiterte erste und der gelungene zweite Versuch zur Unterzeichnung (Herbst 2003 bis Oktober 2004)

Nach der Euphorie über den gelungenen Konvent stand dem Verfassungsvertrag ein ungewisses und, wie sich herausstellen sollte, dramatisches Schicksal bevor. Das lag nicht zuletzt daran, dass die neue Reformmethode des Konvents bekanntlich eingebunden blieb in

44 Das war einer der Gründe dafür, dass die deutschen Bundesländer mit dem Vertrag über eine Verfassung für Europa einverstanden waren. Umfassender dazu Rudolf Hrbek: Die deutschen Länder und der Verfassungsentwurf des Konvent, in: integration 4/2003, S. 357-370.

45 Das Rotationssystem für Kommissare, das der Konvent erfand, befriedigte nur wenige, aber bessere Vorschläge lagen auch nicht vor.

46 Unter den zahlreichen Beiträgen zur Bewertung des Konventsvorschlages stellvertretend: Joachim Jens Hesse: Themenheft: Der „EU-Verfassungskonvent“ - eine erste Bilanz, Zeitschrift für Staats- und Europawissenschaften 3/2003. Mit einigem Abstand bereits Mathias Jopp/Saskia Matl (Hrsg.): Der Vertrag über eine Verfassung für Europa. Analysen zur Konstitutionalisierung der EU, Baden-Baden 2005.

47 Europäischer Konvent: Entwurf eines Vertrags über eine Verfassung für Europa, CONV 850/03. Vom gleichen Datum, dem 18. Juli 2003, stammt auch der Bericht des Vorsitzes des Konvents an den Präsidenten des Europäischen Rates, der eine Zusammenfassung und Bewertung des Verfassungsvertrags aus der Sicht Giscard d'Estaings enthält. Europäischer Konvent: Bericht des Vorsitzes des Konvents an den Präsidenten des Europäischen Rates, CONV 851/03. 
die alte der Regierungskonferenzen. Eine solche wurde im Herbst 2003 einberufen, allerdings nur mit wenigen Wochen Laufzeit, um den Verfassungsvertrag für den Kreis der Staats- und Regierungschefs vorzuberaten, der seinerseits im Dezember 2003 über die unveränderte oder modifizierte Annahme des Entwurfs entscheiden sollte. Auf dem Weg dorthin verlor der Vertrag bereits einige seiner reformatorischen Impulse, so etwa einen mit allgemeiner Gesetzgebung befassten und öffentlich - nach Art einer zweiten (föderalen) Parlamentskammer - tagenden Ministerrat.

Aber im Großen und Ganzen blieb das sorgfältig und mühsam ausgehandelte Gleichgewicht der institutionellen Reformschritte erhalten, bis der Europäische Rat sich im Dezember 2003 unter italienischer Ratspräsidentschaft damit befasste. Silvio Berlusconi, der italienische Ministerpräsident, brach die Sitzung schon am zweiten Tag ab, bevor es noch zu intensiveren Verhandlungen kommen konnte, zum Erstaunen der polnischen Delegation, die gemeinsam mit der spanischen nun gegen den Verfassungsvertrag scheinbar unüberwindliche Bedenken erhob, obwohl doch auch der polnische Regierungsvertreter den Entwurf im Konsens mit verabschiedet hatte. Polen und Spanien hatten durch die Stimmgewichtung im Vertrag von Nizza eine derart übergewichtige Stellung erhalten, dass sich beide Staaten davon nicht wieder trennen wollten das irrationale Arrangement, auf dem Frankreich um der deutsch-französischen Parität willen bestanden hatte, zog eine weitere irrationale Position nach sich, an der die Unterzeichnung des Verfassungsvertrags tatsächlich scheiterte. ${ }^{48}$ Erst als die spanischen Parlamentswahlen die konservative Regierung Aznar Anfang 2004 zum Rücktritt zwangen, der neue sozialistische Ministerpräsident José Luis Rodriguez Zapatero einen konzilianteren europapolitischen Kurs einschlug und nun für Spanien Zustimmung zum Verfassungsvertrag signalisierte, wurde Polen in die nicht mehr haltbare Rolle des einzigen Widerständlers gedrängt und gab seinerseits die Blockade des Vertrags auf. Im Oktober 2004 schließlich konnte der Vertrag in der leicht zurückgenommenen, aber immer noch wesentlich auf dem Konventsvorschlag basierenden Form in Rom feierlich von den Staats- beziehungsweise Regierungschefs unterzeichnet werden. ${ }^{49}$

\section{Die Referenden in Frankreich und den Niederlanden}

Natürlich war damit das Inkrafttreten des Verfassungsvertrags noch nicht gesichert, die alles entscheidende Etappe würde die Ratifizierung sein. Sie begann vielversprechend in Spanien mit einem Referendum, das eine Dreiviertelmehrheit (allerdings bei geringer Beteiligung ${ }^{50}$ für den Vertrag eintrug, und parlamentarischen Ratifizierungsverfahren in anderen Staaten, die nirgends Probleme bereiteten. Einige Mitgliedstaaten galten allerdings als weniger sichere Ratifizierungskandidaten, vor allem Großbritannien, wo gerade die von dort als Vertreterin der nationalen Parlamente ins Konventspräsidium entsandte Gisela Stuart in Publikationen als vehemente Gegnerin des Vertrags auftrat, ${ }^{51}$ aber auch insgesamt die öffentli-

48 Vgl. Andreas Maurer/Simon Schulz: Die Textur der Krise: Europas Verfassungsgebungsprozeß in der Verlängerung, Stiftung Wissenschaft und Politik: SWP-Diskussionspapier der FG 1 2004/2, Februar 2004.

49 Vgl. die kommentierte und in der Einführung auch die Entwicklung noch einmal resümierende deutsche Textausgabe von Thomas Läufer: Verfassung der Europäischen Union. Verfassungsvertrag vom 29. Oktober 2004. Protokolle und Erklärungen zum Vertragswerk, Bonn 2005.

50 Die, Ja'-Stimmen machten 77 Prozent der abgegebenen Stimmen aus, die Wahlbeteiligung lag bei 42 Prozent. Vgl. Europäische Kommission: The European Constitution: post-referendum survey in Spain, Flash Eurobarometer 168, Fieldwork: 21-22 February 2005, Publication: March 2005.

51 Vgl. zu dieser Kontroverse Gisela Stuart: The Making of Europe's Constitution, London 2003, und die Antwort des (ebenfalls britischen Labour-Abgeordneten im Europäischen Parlament) Richard Corbett: The Case for Europe's Constitution: a response to Gisela Stuart. Vgl. auch John Palmer: The , nation "state is not enough: a reply to Gisela Stuart, 02.12.2005, abrufbar unter: http://www.opendemocracy.net/democracy-europe_consti tution/stuart_reply_3086.jsp (letzter Zugriff: 31.01.2011). 
che Meinung wie die politische Elite skeptisch blieb. Ob es hier ein Referendum geben sollte, blieb lange offen, ebenso die Frage, wann die endgültige Entscheidung fallen sollte der Vertrag selbst sah eine rund zweijährige Ratifizierungsperiode vor, nach deren Ablauf, sollten Schwierigkeiten auftreten, sich die Staats- und Regierungschefs erneut mit dem Verfassungsvertrag befassen sollten. Polen, unter der Regierung der Brüder Jarosław und Lech Kaczyński, blieb trotz seiner Unterzeichnung sehr zurückhaltend im Ratifizierungsprozess, ${ }^{52}$ ebenso wie die Tschechische Republik, deren Präsident Václav Klaus ein entschiedener Gegner aller weiteren Integrationsschritte war.

Dass allerdings der Verfassungsvertrag in zwei Gründungstaaten der ersten Gemeinschaftsbildung, in Frankreich und in den Niederlanden, scheitern würde, war eine katastrophale Überraschung. Chirac entschied sich im Herbst 2004 dafür, den Verfassungsvertrag zum Gegenstand einer Volksabstimmung zu machen. Zwar zwang ihn die französische Verfassung nicht dazu, aber die öffentliche Meinung in Frankreich drängte angesichts der fundamentalen Bedeutung einer supranationalen Verfassungsbildung darauf, eine solche Entscheidung zur Angelegenheit des ganzen (Wahl-)Volkes zu machen. Und in Umfragen zeigte sich zu dieser Zeit ungefähr eine Zweidrittelmehrheit für den Vertrag. In den Niederlanden war die Öffentlichkeit von Anfang an skeptischer, ein Misstrauen gegen eine zu weitgehende politische Union mit zu wenig Autonomie (von Souveränität nicht zu reden) der Mitgliedstaaten prägte die Perzeption der europäischen Verfassung hier.

Nachdem Chirac das Referendum anberaumt hatte, setzte eine Kampagne gegen den Verfassungsvertrag ein, die letztlich am 29. Mai 2005 bei der Abstimmung eine deutliche Mehrheit - 54 Prozent - auf die Seite der Ablehnung zog, ${ }^{53}$ drei Tage danach noch einmal übertroffen von über 60 Prozent der niederländischen Wahlbeteiligten. ${ }^{54}$ Über die Motive der ,Nein'-Sager ist viel geschrieben und diskutiert worden, das Aufsehen war in ganz Europa groß und die Betroffenheit besonders bei den politischen Eliten vergleichbar mit dem Schock nach der Ablehnung der Europäischen Verteidigungsgemeinschaft, ebenfalls in Frankreich, im August 1954. Zunächst hatte der Verfassungsvertrag eine seiner entscheidenden Schwächen offenbart und damit den Gegnern das Spiel leicht gemacht: In den Kampagnen konnte man die absurdesten Behauptungen über bedrohliche Inhalte und Bestimmungen des Vertrags hören, weil sich die Propagandisten annähernd sicher sein konnten, dass der Vertrag für ,normale Bürger" unlesbar war und sie deshalb nicht würden überprüfen können, was behauptet wurde. Ein zweiter wesentlicher Faktor war Chirac selbst. Drei Jahre zuvor war er mit einer Mehrheit von über 82 Prozent wieder ins Amt gewählt worden, und zwar deshalb, weil im ersten Wahlgang zum Entsetzen sehr vieler Franzosen nicht der sozialistische Kandidat Jospin auf dem zweiten, zum Einzug in die zweite Runde berechtigenden Platz landete, sondern der Kandidat der extremen Rechten, Jean-Marie Le Pen. Im zweiten Wahlgang stimmten des-

52 Zu Lech Kaczynskis Auffassungen siehe seine Rede an der Humboldt-Universität vom 6. März 2006. Vgl. Deutsche Nationalstiftung/Humboldt-Universität zur Berlin/Walter Hallstein-Institut (Hrsg.): Humboldt-Rede zu Europa von Lech Kaczynski Präsident der Republik Polen „Solidarisches Europa“, 6. März 2006; Vaclav Klaus' langfristige Auffassungen finden sich u.a. in seinem Interview in der Frankfurter Allgemeinen Zeitung vom 20. Juni 2007. Vgl. Frankfurter Allgemeine Zeitung: „Die Stimmengewichtung ist nicht entscheidend“, Václav Klaus im Interview, 20.06.2007.

53 Zum französischen Referendum vgl. Joachim Schild: Ein Sieg der Angst - das gescheiterte französische Verfassungsreferendum, in: integration 3/2005, S. 187-200; Europäische Kommission: The European Constitution: Post-referendum survey in France, Flash Eurobarometer 171, Fieldwork: 30 \& 31 May 2005, Publication: June 2005; Ipsos ASI: Référendum 29 Mai 2005: Le sondage sorti des urnes. Les chiffres et résultats complets du sondage, abrufbar unter: http://www.ipsos.fr/CanalIpsos/poll/8074.asp (letzter Zugriff: 31.01.2011).

54 Umfrageergebnisse in Flash Eurobarometer: Europäische Kommission: The European Constitution - Postreferendum Survey in The Netherlands, Flash Eurobarometer 172, Fieldwork 2-4 June 2005, Publication June 2005. 
halb nahezu alle sozialistischen Wähler mit zusammengebissenen Zähnen für den ungeliebten Gaullisten Chirac - und warteten seitdem auf die nächste Gelegenheit, um ihm selbst oder einem von ihm vorgeschlagenen politischen Projekt den Garaus zu machen. Diese nächste Gelegenheit war der von Chirac propagierte Verfassungsvertrag. Drittens waren die Sozialisten selbst im Hinblick auf den Vertrag gespalten beziehungsweise gespalten worden, wie man sagen muss, von dem früheren Premierminister Laurent Fabius, der in einer spektakulären und eigentlich auch die Mehrheitsmeinung seiner eigenen Partei ignorierenden Aktion seine eigene sinkende Sichtbarkeit in der französischen Politik wieder so weit aufbessern wollte, dass ihm eine künftige Präsidentschaftskandidatur möglich würde. ${ }^{55}$ Delors, Michel Rocard und andere europäische Sozialisten wehrten sich nach Kräften gegen dieses Manöver, aber beim Referendum stimmten viele sozialistische Wähler (wenige gaullistische) gegen die Verfassung und folgten damit Fabius. Neben diese Umstände politischer Konjunktur trat aber auch ein tieferliegendes Unbehagen der französischen Wählerschaft, das sich nur sehr diffus auf die Europäische Union (und noch weniger auf Europa und europäische Integration als solche) bezog, vielmehr mit Ängsten hinsichtlich der wirtschaftlichen Entwicklung, ihrer sozialen Folgen, mit Befürchtungen des Ausgeliefertseins an eine zunehmend als bedrohlich empfundene Globalisierung zu tun hatten. Der Verfassungsvertrag wurde, wenn auch irrtümlich, als Teil des Problems und nicht als Schritt zur Lösung angesehen. Fabius spielte vor allem mit diesen Motiven und erklärte sich, der er doch als Premierminister den Vertrag von Maastricht mitsamt seinem ordnungspolitischen Kurs unterzeichnet hatte, nun zum Anwalt sozialer Verantwortung gegenüber dem angeblich allzu (neo-)liberalen Europa.

\section{Von den gescheiterten Referenden zum Vertrag von Lissabon}

Trotz des Debakels in Frankreich und den Niederlanden kam der Ratifizierungsprozess nicht zum Erliegen, auch wenn die Skeptiker in Großbritannien, Polen und der Tschechischen Republik in den gescheiterten Referenden einen willkommenen Anlass sahen, die Ratifikation in ihren Staaten auf unbestimmte Zeit zu verschieben. Andere dagegen bemühten sich, durch die Ratifizierung in ihrem Lande dem Eindruck entgegenzuwirken, dass der Kollaps des Reformprozesses unvermeidlich sei. Der luxemburgischer Premierminister Jean-Claude Juncker brachte den politischen Mut auf, wenige Wochen nach den gescheiterten Referenden in Frankreich und den Niederlanden und vor dem Referendum in seinem Land seinen Rücktritt anzukündigen, sollte die Volksabstimmung scheitern. Sie ging positiv aus, ${ }^{56}$ ebenso wie die parlamentarischen Ratifizierungen in anderen Staaten, sodass Ende des Jahres 200518 von (zukünftig) 27 Mitgliedstaaten, mithin zwei Drittel, den Verfassungsvertrag ratifiziert hatten - eine Lage, die jedenfalls nicht erlaubte, die Verfassung für obsolet zu erklären.

Inzwischen hatten die Staats- und Regierungschefs, unmittelbar nach der französisch-niederländischen Ablehnung, eine einjährige ,Reflexionsphase ' anberaumt. ${ }^{57}$ Es war indessen klar, dass vor dem Ende der Amtszeit von Chirac im Frühjahr 2007 keine neue Initiative

55 Zur Kontroverse in der französischen Parti Socialiste Amandine Crespy: Dissent over the European Constitutional Treaty within the French Socialist Party: Between Response to Anti-Globalization Protest and IntraParty Tactics, in: French Politics 1/2008, S. 23-44.

5656 Prozent ,Ja'-Stimmen. Vgl. Europäische Kommission: Die europäische Verfassung: Umfrage nach dem Referendum in Luxemburg, Flash Eurobarometer 173, Befragung: 11.-18. Juli 2005, Veröffentlichung: Juli 2005.

57 Die Reflexionsphase wurde beschlossen und bekannt gegeben in der Declaration by the Heads of State or Government of the Member States of the European Union on the Ratification of the Treaty establishing a Constitution for Europe, Brussels, 18 June 2005, SN 117/05. Vgl. auch Barbara Einhäuser/Geraldine Vivien Salborn: Der Europäische Verfassungsvertrag und die Reflexionsphase der Europäischen Union. Sachstand und Stimmungen in den einzelnen Mitgliedsstaaten der Europäischen Union, Konrad-Adenauer-Stiftung, Europabüro, Brüssel, Juni 2006. 
mehr Bewegung in die französische Position würde bringen können. Das Dilemma lag darin, dass es ja nicht eigentlich der Verfassungsvertrag selbst war, der die Ablehnung hervorgerufen hatte - entweder er war nicht verstanden oder verfälscht worden und die wesentlichen Motive des Widerwillens in den Wählerschaften bezogen sich auf die nationale, nicht die europäische Ebene. Unter diesen Umständen am Verfassungsvertrag selbst Änderungen vorzunehmen, die die Vorbehalte in den Problemstaaten ausräumten und dabei auch noch den in aller Form bekundeten Willen derer zu respektieren, die ratifiziert hatten, kam der Quadratur des Zirkels gleich. Die ,Reflexionsphase" wurde denn auch im Jahr darauf um ein weiteres Jahr verlängert, allerdings mit einer Nuance: Im Juni 2006, unter österreichischer Ratspräsidentschaft, ${ }^{58}$ wurde der deutschen Ratspräsidentschaft für das erste Halbjahr 2007 - also in der Periode, in der sich die französischen Verhältnisse klären würden - aufgetragen, eine Marschroute festzulegen, auf der dann wiederum ein Jahr später, im zweiten Halbjahr 2008 - unter französischer Ratspräsidentschaft - der Reformprozess zu einem erfolgreichen Ende würde geführt werden können. Die Eile war geboten, weil man hoffte, den Reformvertrag noch vor den Wahlen zum Europäischen Parlament und der Neubestimmung der Europäischen Kommission 2009 in Kraft setzen zu können, sodass beide Institutionen nach den neuen Regeln ins Amt gekommen wären.

Dieser Aufgabe widmete sich die deutsche Ratspräsidentschaft unter der Ägide Angela Merkels mit großem Geschick und fast unerwartetem Erfolg, auch wenn das Ergebnis nichts anderes als eine hybride Konstruktion sein konnte - der Verfassungsvertrag, reduziert um alles, was auch nur im Entferntesten an ein staatsähnliches politisches Gebilde erinnerte, in der Verkleidung eines konventionellen Vertrags, wie ihn die europäische Integration schon oft gesehen hatte. ${ }^{59}$ Der Weg dorthin war natürlich dornenreich und verlangte eine ausgeklügelte Dramaturgie über das Halbjahr der deutschen Ratspräsidentschaft hinweg, mit einem ersten Höhepunkt anlässlich des 50. Jahrestages der Römischen Verträge im März 2007, dem Anlass für eine gemeinsame Erklärung. ${ }^{60}$ Überhaupt beförderte den weiteren Prozess das Erlebnis wieder gewonnener Gemeinsamkeit in Verbindung mit einer diskreten Analyse dessen, was in allen Mitgliedstaaten für verdaulich gehalten wurde, sowie einer ebenso vertraulichen Vorbereitung der letztendlich vorzulegenden Vorschläge und einer abschließenden Gipfelregie, bei der einmal mehr nächtliche Verhandlungen und gar Telefonate zwischen Brüssel und Warschau das ultimative Einvernehmen über den ,neuen` Reformvertrag herstellen mussten. ${ }^{61}$ Das war weit mehr als die deutsche Ratspräsidentschaft aufgetragen bekommen hatte. Am Ende stand nicht nur eine ,roadmap', sondern ein schon so weit präzisiertes Mandat ${ }^{62}$ für eine dann fast nur noch vertragstechnische Regierungskonferenz, dass im Grunde politische Konflikte nicht mehr zu befürchten waren. Im Oktober 2007 stand der

58 Rat der Europäischen Union: Europäischer Rat (Brüssel) 15./16. Juni 2006. Schlussfolgerungen des Vorsitzes, Dok. 10633/1/06.

59 Das Europäische Parlament setzte sich bis zuletzt für einen möglichst unversehrten Erhalt des Verfassungsvertrags ein. Vgl. Europäisches Parlament, Ausschuss für konstitutionelle Fragen: Bericht über die Roadmap für den EU-Verfassungsprozess, Berichterstatter: Enrique Barón Crespo/Elmar Brok, A6-0197/2007.

60 Rat der Europäischen Union: Informelles Treffen der Staats- und Regierungschefs Berlin, 24./25. März 2007. Erklärung Anlässlich des 50. Jahrestages der Unterzeichnung der Römischen Verträge, Brüssel, 25. März 2007.

61 Zur Aufarbeitung siehe die Bilanz der deutschen EU-Ratspräsidentschaft. Vgl. Bertelsmann Forschungsgruppe Politik: Bilanz der deutschen EU-Ratspräsidentschaft Analyse und Bewertung des Centrums für angewandte Politikforschung, C.A.P Analyse 6/2007; Wolfgang Wessels/Anne Faber: Vom Verfassungskonvent zurück zur ,Methode Monnet'? Die Entstehung der ,Road Map' zum EU-Reformvertrag unter deutscher Ratspräsidentschaft, in: integration 4/2007, S. 370-381.

62 Rat der Europäischen Union: Europäischer Rat (Brüssel) 15./16. Juni 2006. Schlussfolgerungen des Vorsitzes, Dok. 10633/1/06. 
Reformvertrag und als er im Dezember 2007 in Lissabon unterzeichnet wurde, wurde er wie üblich auf den Namen dieser Stadt getauft.

Die Substanz war sehr weitgehend immer noch die des Verfassungsvertrags, das institutionelle Gefüge war unverändert ebenso die Entscheidungsverfahren, die Einbindung der nationalen Parlamente und die Kompetenzverteilung zwischen Staaten und Union. Was sich geändert hatte, war im Wesentlichen die Form und dafür ist eine Formel im Entwurf des Mandats, das nach der deutschen Ratspräsidentschaft an die Regierungskonferenz zur Umarbeitung des Verfassungsvertrags ergehen sollte, schlaglichtartig aufschlussreich: Dort heißt es „,der ,Außenminister der Union“ wird ,Hoher Vertreter der Union für Außen- und Sicherheitspolitik' genannt." ${ }^{63}$ Das bedeutet nichts anderes, als dass es einen Außenminister wirklich geben soll, dass er aber nicht so genannt werden darf - die begriffliche Wahrhaftigkeit des Verfassungsvertrags wird wieder rückgängig gemacht. Gesetze werden wie früher ,Richtlinien' genannt, der Verfassungsbegriff wird ebenso eliminiert wie alle Symbole (Fahne, Hymne, et cetera) die sonst nur Staaten zukommen. Vor allem aber wird die Einheitlichkeit des Vertragstexts aufgegeben und die bestehende alte Form vielgliedriger Vertragskonstruktionen weitergeführt, in der Gestalt eines umfassenden Vertrags über die Europäische Union ${ }^{64}$ und eines zweiten Vertrags über die Arbeitsweise der Union, der im Wesentlichen den bisherigen Vertrag über die Europäische Gemeinschaft oder, in der Komposition des Verfassungsvertrags dessen dritten Teil fortführt. Insgesamt ergibt sich daraus zwar die Rettung der politischen Substanz der jahrelangen Reformbemühungen, aber um den Preis des Verzichts auf jeglichen Zuwachs an Transparenz, Vereinfachung und Verständlichkeit - das war immerhin eines der großen Reformmotive am Anfang des Prozesses und hatte noch in der „Erklärung zur Zukunft der Union“ in Nizza seinen Platz gefunden.

Der Vertrag von Lissabon erfüllte aber die Voraussetzungen, die vor allem von den Staaten gefordert worden waren, in denen Referenden den Verfassungsvertrag zum Scheitern gebracht hatten: Nicolas Sarkozy, der Nachfolger Chiracs, konnte nun der vorfranzösischen Wählerschaft ebenso wie seine niederländischen Kollegen vor der ihren, die Position vertreten, dass es sich bei diesem Vertrag nicht mehr um eine Verfassung, sondern um den von ihm herbeigewünschten ,Mini-Traité ' handele, dass ein solcher Vertrag weit unterhalb der Schwelle dessen liege, was unabänderlich dem Entscheid des Volkes überantwortet werden müsse, dass diesem Vertrag eine parlamentarische Ratifizierung angemessen sei. ${ }^{65}$ Am 7. Februar 2008 ratifizierte das französische Parlament den Vertrag von Lissabon, für das erste der, großen` EU-Mitgliedstaaten.

Dass der Ratifizierungsmarathon, der wiederum so hoffnungsvoll begonnen hatte, auch dieses Vertrags an einer Volksabstimmung zum Halten kommen würde, war eine umso größere Enttäuschung. Irland ist seiner eigenen Verfassung nach zum Referendum verpflichtet, und wiederum ist hier am 12. Juni 2008, wie schon beim Vertrag von Maastricht, die Con-

63 Ebenda § 3. Im selben Abschnitt wird die Aufgabe der Begrifflichkeit des Verfassungsvertrags auch für die Gesetzgebung und für den Begriff „Verfassung“ selbst in Auftrag gegeben.

64 Vertrag von Lissabon, in: Amtsblatt der EU, Nr. C 306 vom 17. Dezember 2007; Vertrag über die Europäische Union und Vertrag über die Arbeitsweise der Europäischen Union in: Amtsblatt der EU, Nr. C 83 vom 30. März 2010; als erste Bewertung und Analyse Peter-Christian Müller-Graff: Der Vertrag von Lissabon auf der Systemspur des Europäischen Primärrechts, in: integration 2/2008, S. 123-144.

65 Siehe die Rede Sarkozys in Brüssel vom 8. September 2006, in der er den Weg von den gescheiterten Referenden zu einem erfolgreichen Reformvertrag entwirft. Vgl. Nicolas Sarkozy: L'Europe de demain - Une nouvelle vision française, Rede bei Friends of Europe und der Fondation Robert Schuman, 8. September 2006, Brüssel. Rückendeckung erhielt Sarkozy unter anderem vom früheren (sozialistischen) Kommissionspräsidenten Jacques Delors, vgl. RTL.fr: Jacques Delors: „Le mini-traité permet à l'Europe de sortir de son coma allégé“, 04.02.2008, abrufbar unter: unter http://www.rtl.fr/fiche/39773/jacques-delors-le-mini-traite-permet-a-1europe-de-sortir-de-son-coma-allege.html (letzter Zugriff: 31.01.2011). 
tra-Kampagne erfolgreich gewesen, wiederum auch hier aufgrund einer Verquickung innenund europapolitischer Motive, die weniger oder gar nicht rationaler sind als die französischen und niederländischen. Bei 53 Prozent Wahlbeteiligung stimmten 53 Prozent der Beteiligten gegen den Vertrag. ${ }^{66}$ Bevor das irische Problem lösbar wurde, tauchten allerdings unerwartet anderswo Hürden auf, nämlich in Deutschland.

Am 24. April 2008 ratifizierte der Deutsche Bundestag und am 23. Mai 2008 (am bundesdeutschen Verfassungstag also) der Bundesrat den Vertrag von Lissabon - allerdings war damit der Weg noch nicht frei für sein Inkrafttreten: Beim Bundesverfassungsgericht wurde eine Klage eingereicht und angenommen, am 30. Juni 2009 erging ein kompliziertes Urteil, ${ }^{67}$ das zwar den Vertrag selbst für grundgesetzkompatibel erklärte, nicht aber das deutsche Begleitgesetz dazu, das die rechtliche Bedingung für das Inkraftsetzen des Vertrags und seine Geltung in Deutschland darstellt. Darin müsse sichergestellt werden, so das höchste deutsche Gericht, dass nationalstaatliche parlamentarische Prärogativen erhalten blieben; und im Übrigen sei jeder weitere substanzielle Integrationsschritt ein Schritt über das Grundgesetz hinaus, sodass dann eine verfassunggebende Entscheidung des Volkes nötig werde. In aller Eile einigten sich die deutsche Große Koalition, die Bundesländer und Oppositionsparteien (nur „Die Linke“ hatte einen abweichenden Gesetzesentwurf eingebracht) auf das Integrationsverantwortungsgesetz, das den Forderungen des Bundesverfassungsgerichts Rechnung trug, demzufolge der Bundestag bei grundlegenden Machtverschiebungen zwischen nationaler und europäischer Ebene seine ausdrückliche Zustimmung geben muss, bevor die Bundesregierung ihrerseits zur Zustimmung in den europäischen Institutionen berechtigt ist. Auch die Länder erhalten nochmals weitergehende Mitbestimmungsrechte. ${ }^{68}$ Am 1. Oktober 2009 konnten die insgesamt vier einzelnen Gesetze in Kraft treten - einen Tag vor dem zweiten irischen Referendum, denn von hierher kam der enorme Zeitdruck auf die deutsche Ratifizierung. ${ }^{69}$

Irland unterzog sich schließlich dem peniblen Verfahren eines zweiten Referendums ${ }^{70}$, und diesmal dank viel früherem und energischerem Einsatz der Regierung (und vieler anderer Mitstreiter) mit Erfolg: Am 2. Oktober 2009 stimmten 67,1 Prozent der Abstimmenden für den Vertrag, der nun nicht mehr aufzuhalten war. Am 3. November 2009 unterzeichnete schließlich nach einem positiven Verfassungsgerichtsurteil in Tschechien auch Klaus als letzter unter den europäischen Staatspräsidenten (oder sonstigen Unterschriftsberechtigten) die tschechische Ratifizierungsurkunde, sodass der Vertrag am 1. Dezember 2009 in Kraft treten konnte.

„His [Klaus'] signature ends a far too long period of institutional focus within the EU. It opens up for a more democratic, transparent and efficient Union," sagte Fredrik Reinfeldt,

66 Die Ergebnisse und Motive im Einzelnen in Europäische Kommission: Post-referendum survey in Ireland. Analytical Report, Flash Eurobarometer 245, Fieldwork: 13-15 June 2008, Report: July 2008; ein von der irischen Regierung in Auftrag gegebener Bericht über die Ursachen der Ablehnung fördert erstaunliche Einflüsse auf das Verhalten der irischen Wähler zutage, so etwa von der aus neokonservativen amerikanischen Kreisen finanzierten Organisation „Libertas“.

67 Zum Urteil des Bundesverfassungsgerichts siehe exemplarisch Peter-Christian Müller-Graff: Das Karlsruher Lissabon-Urteil: Bedingungen, Grenzen, Orakel und integrative Optionen, in: integration 4/2009, S. 331-360.

68 Vgl. Sebastian Gröning-von Thüna: Die neuen Begleitgesetze zum Vertrag von Lissabon aus Sicht des Deutschen Bundestages - offene Fragen und neue Herausforderungen, in: integration 4/2010, S. 312-333.

69 Der Bundespräsident hatte die Ratifikationsurkunde schon am 23. September 2009 unterzeichnet, als die Gesetze im Bundestag angenommen worden waren, die deutsche Urkunde wurde zwei Tage später in Rom hinterlegt.

70 Vgl. Wolf J. Schünemann: Wieder ein Sieg der Angst? Das zweite irische Referendum über den Lissabon-Vertrag in der Analyse, in: integration 3/2010, S. 224-239. 
schwedischer Premierminister und zu dieser Zeit Ratspräsident. ${ }^{71}$ Weiter noch als der letzte ,rotierende' Präsident des Europäischen Rates ging der Präsident des Europäischen Parlaments in der Bezeugung seiner Erleichterung: „Die Institutionendebatte ist endlich vorbei“, wurde Jerzy Buzek zitiert, ${ }^{72}$ sodass sich die Europäische Union ,endlich auf die wahren Probleme konzentrieren kann, denen sich unsere Bürger gegenüber sehen. “ Aber ist - und bleibt - nicht auch die Frage nach der Verfasstheit, der Verfassung, der politischen Natur, der demokratischen Struktur der Europäischen Union ein ,wahres Problem“?

\section{Rück- und Ausblick}

Die Systemreform der letzten Dekade füllt natürlich nicht allein das Kapitel Integrationsgeschichte, das es für diese Zeit zu schreiben gilt. Hier wurde der Vertragsreformprozess künstlich isoliert. Daneben gab es immerhin so wichtige Etappen wie die große Erweiterung um Ostmitteleuropa (die die Systemreform eigenartigerweise wenig beeinflusst zu haben scheint) und so anspruchsvolle Politikversuche wie die Lissabon-Agenda, die in der Euphorie der Jahrtausendwende entworfen wurde und die Europäische Union zum innovativsten und wettbewerbsfähigsten Wirtschaftsraum der Welt machen sollte. Dies war ein Politikprojekt, das sich durchaus als legitimer Nachfolger von Binnenmarkt und Währungsunion verstehen lässt, allerdings eben diesmal nicht mit der Systemreform verknüpft wurde und sich nicht auf vertraglich abgesichertes europäisches Recht stützen konnte (von allen anderen Illusionen abgesehen). ,Soft law " und die Methode der offenen Koordinierung sind die Stichworte (nicht nur) für die Lissabon-Agenda, Verfahren, die einer dichteren vertraglichen Bindung, einer Föderalisierung, eine Absage erteilen. In der Divergenz zwischen konkreter Integrationspolitik und dem Anspruch auf Verfassungsbildung ist vielleicht ein tieferer Grund für das Scheitern des Verfassungsvertrags zu suchen.

Inzwischen ist der Vertrag von Lissabon selbst Ausgangspunkt von neuester Geschichte geworden. Zunächst gilt das für die Implementierung der Vertragsbestimmungen, die im Vergleich zu früheren Verträgen die Besonderheit aufweisen, dass sie Übergangsperioden und Versuchsphasen initiieren, Margen für die Ausfüllung von institutionellen und funktionalen Schaltstellen lassen. Ein Beispiel dafür ist das neue Amt des permanenten Präsidenten des Europäischen Rates, ${ }^{73}$ dessen Rolle wesentlich von ihrer Besetzung abhängt - man kann sie als Moderator oder als Motor interpretieren, als Integrationsdynamiker oder als Dienstleister für die Mitgliedstaaten und entsprechende Persönlichkeiten auswählen. Ähnliches gilt für das Amt des Außenministers, der nicht so heißen darf (und ja auch nicht wirklich die Kompetenzen hat, die den Begriff rechtfertigen würden). Ein anderes Beispiel ist die institutionelle Lokalisierung des Europäischen Auswärtigen Dienstes, ${ }^{74}$ dessen Nähe oder Ferne zu Rat, Parlament und Kommission vermutlich mit ausschlaggebend ist für seine integrationspolitische Rolle. Man wird also, in der Fortsetzung der Geschichte der Systemreform, diese

71 Andrew Willis: Klaus signature completes EU treaty ratification, eu.observer, 03.11.2009. Auch die Hoffnung der britischen Konservativen, das Inkrafttreten des Vertrags durch Verzögerungen bei der Ratifizierung bis zu einem voraussehbaren Wahlsieg im Jahr 2010 hinauszögern zu können, um den Vertrag dann noch scheitern zu lassen, ließen sich nach Klaus' wenn auch widerwilliger Entscheidung nicht mehr realisieren.

72 Agence Europe: EU/European Council: Varying reactions to appointments - Ashton intends to put on ,second half" from 1 December 2009, 21.11.2009, S. 4.

73 Wolfgang Wessels/Thomas Traguth: Der hauptamtliche Präsident des Europäischen Rates: ,Herr‘ oder ,Diener" im Haus Europa?, in: integration 4/2010, S. 297-311.

74 Julia Lieb/Martin Kremer: Der Aufbau des Europäischen Auswärtigen Dienstes: Stand und Perspektiven, in: integration 3/2010, S. 195-208. 
heute noch nicht abgeschlossene Phase der Implementierung des Vertrags von Lissabon, seiner Interpretation und Bewährung ein eigenes Kapitel widmen müssen.

Schließlich sieht sich die Europäische Union einer ganz anderen, unerwarteten Herausforderung gegenüber, die die Lissabon-Agenda auch in ihrer bescheideneren, revidierten Fassung gänzlich hinter sich lässt: die globale Finanz- und Wirtschaftskrise seit dem Herbst 2008. Sie brach aus bevor der neue Vertrag in Kraft trat und nährt doch schon kaum ein Jahr später Zweifel daran, ob dieser Vertrag die Europäische Union auch angesichts von Herausforderungen dieser Dimension handlungsfähig macht. Solange die Krisenreaktion darin bestand, Unsummen an Budgetmitteln zu mobilisieren, um den Brand schnellstmöglich zu löschen, schienen die Mitgliedstaaten die privilegierten Akteure zu sein, die Krisengewinner sozusagen, die sich als die machtvollen Bewältiger der Krise zeigen konnten: Nur sie, die Staaten, nicht aber die Europäische Union, verfügen über solche Budgets, wie sie zum Löschen des Brandes auf das Feuer geschüttet werden mussten. Aber schon in der zweiten Phase der Krise wurden die Staaten selbst - die wirtschaftlich und finanziell schwächsten unter ihnen zuerst - in den Strudel der Krise gerissen; der zweiten Stützaktion, die noch einmal atemberaubende Summen mobilisierte, wird kaum eine dritte folgen können: Die europäischen Staaten haben sich verausgabt. Es ist deshalb nicht verwunderlich, dass nun eine Krisenbewältigungsstrategie in den Vordergrund tritt, die nicht auf monetäre Massen, sondern auf Regulierung der (Finanz-)Märkte zielt - und auf dem Gebiet Regulierung ist die Europäische Union stark, machtvoller womöglich als die Mitgliedstaaten. Kein Wunder also, wenn der Europäischen Union die Krisenlösung zugemutet und aufgetragen wird, allerdings stellt sich sogleich die Frage, ob dazu die vertraglichen Grundlagen ausreichen. Die Antwort ist unangenehm, weil negativ: Kaum in Kraft getreten, muss der Vertrag von Lissabon schon wieder revidiert werden, schon ist von einer echten Wirtschaftsregierung die Rede, für die doch erst die Kompetenzen auf europäischer Ebene geschaffen werden müssen. Aber mit den Optionen einer erneuten Vertragsreform öffnet sich definitiv ein neues Kapitel der Integrationsgeschichte, das über den zeitlich und sachlich begrenzten Horizont dieses Beitrags hinausgeht.

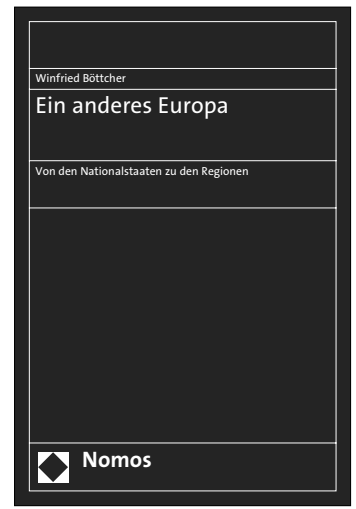

\section{Ein anderes Europa}

Von den Nationalstaaten zu den Regionen Von Winfried Böttcher unter Mitarbeit von Johanna Krawczynski 2011, 257 S., brosch., 44, - €, ISBN 978-3-8329-6147-3

Der Autor legt dar, dass das Europa der Zukunft regional und föderal sein muss, um ein Scheitern zu verhindern.

Bitte bestellen Sie im Buchhandel oder versandkostenfrei unter $\downarrow$ www.nomos-shop.de

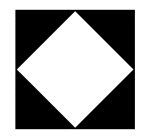

